\title{
Editorial
}

\section{Classification of Specific Cutaneous Manifestations in Patients with Lupus Erythematosus: A Time for Change?}

\author{
The Concept of Dermal Lupus Erythematosus
}

\author{
Dan Lipsker \\ Clinique Dermatologique et Faculté de Médecine, Université Louis-Pasteur, Strasbourg, France
}

In this issue of Dermatology, Caputo et al. [1] report a brother and a sister with reticular erythematous mucinosis (REM) syndrome. HLA typing revealed that both had a haplotype predisposing to auto-immune disease, thus raising the question of the relationship between REM syndrome and auto-immune diseases, especially lupus erythematosus (LE).

This clinically characteristic entity was first reported by Perry et al. in 1960 [2] while Steigleder et al. [3] named it REM syndrome in 1974. It starts usually as red macules and/or papules or plaques that slowly enlarge in the presternal area and/or the mid-upper back. While enlarging, a reticular configuration of the erythema becomes typically apparent. Microscopic evaluation reveals a moderately intense lymphocytic inflammation around superficial and sometimes mid-dermal vessels and mucin deposition in the upper dermis.

Since its initial description, some authors stipulated that the REM syndrome is merely a variant of LE. This assumption relies on the following observations, that are shared with LE: (1) REM is a photosensitive entity and patients usually respond to antimalarial drugs [4]; (2) some patients had associated myalgia, arthralgia or polyarthritis [5]; (3) hormone dependency was reported [6]; (4) some patients had a lupus band on immunofluorescence studies [7]; (5) auto-immune diseases, including thrombopenic purpura and auto-immune thyroiditis are sometimes associated [8-10]; (6) furthermore, REM occurred in patients with discoid, subacute and systemic LE [11], and (7) another entity characterized by dermal mucin deposition, though clinically different, the papulonodular mucinosis, is significantly associated with LE $[12,13]$.

Familial occurrence seems rare in patients with the REM syndrome, as this is the first of such a report. However, familial occurrence has been reported in many families of patients with Jessner's lymphocytic infiltrate of the skin (JLI) [14-16]. JLI is another entity the autonomy of which is subjected to debate since its initial description by Jessner and Kanof in 1953 [17]. It consists of erythematous arciform plaques, mainly located in the head and neck region and on the trunk. Pathological evaluation shows a dense, sleeve-like lymphocytic infiltrate around the superficial and deep dermal vessels. For reasons very similar to those just mentioned above for the REM syndrome, many authors thought of it as being a variant of LE. We have recently shown that 16 out of $210(7.6 \%)$ patients with JLI do have associated LE [18]. Considering that the prevalence of LE is about 1/50,000, the frequency of this association is not fortuitous. This suggests that JLI might be a dermal variant of LE. As only 2 out of the 16 patients with JLI and LE had more than 4 American College of Rheumatology criteria of systemic LE, it is probably an LE subset with a favourable prognosis. Clin-

\section{KARGER \\ Fax +4161306 1234 E-Mail karger@karger.ch} www.karger.com
(C) 2006 S. Karger AG, Basel

$1018-8665 / 06 / 2124-0324 \$ 23.50 / 0$

Accessible online at: www.karger.com/drm
D. Lipsker

Clinique Dermatologique

1, place de l'hôpital

FR-67091 Strasbourg Cedex (France)

Tel. +33 388116179 , Fax +333881159 62, E-Mail dlipsker@noos.fr 
Table 1. Classification of the specific lesions of LE, including dermal LE

Dermo-epidermal LE
Acute
Subacute
Chronic
Indeterminate
LE-specific vesiculobullous disease
Dermal LE
Tumid LE
Jessner's lymphocytic infiltrate of the skin
Papulonodular mucinosis of LE
Reticular erythematous mucinosis syndrome
Hypodermal LE
Lupus panniculitis

ically and pathologically, JLI resembles lupus tumidus, and some authors consider that they are one and the same entity $[19,20]$. Lupus tumidus is characterized by erythematous papules, nodules and plaques in the same distribution as JLI. Microscopically, there is a lymphocytic infiltrate of the dermis with mucin deposition [20].

The current classification of cutaneous lesions occurring in patients with LE was proposed nearly 30 years ago by Gilliam [21]. This classification was a real progress and one of its achievements was to individualize specific lesions of LE, which by themselves allow a diagnosis of LE in the absence of any extracutaneous finding. Specific lesions are usually classified in acute, subacute and chronic LE, defining more or less homogenous disease subsets, with immunopathological and prognostic significance.
However, the REM syndrome, the papulonodular mucinosis (of LE) and JLI are yet not included in the list of specific lesions of LE.

This is mainly because those lesions are lacking, from the pathological point of view, an interface dermatitis, e.g. an inflammatory infiltrate at the epidermal-dermal junction, with vacuolization of basal keratinocytes and some degree of epidermal necrosis. However, more than $50 \%$ of patients with a lupus panniculitis [22] and all patients with lupus tumidus [20], two manifestations of LE considered as specific, lack this interface dermatitis, the hallmark of the so-called specific lesions. Therefore, from a logical point of view, this classification is not coherent. In our opinion, the time has come to expand the concept of the specific cutaneous manifestations of LE and to include purely dermal variants of LE. Dermal LE includes the entities JLI, lupus tumidus, the papulonodular mucinosis of LE and the REM syndrome. From a pathological point of view, the spectrum of dermal LE ranges from lymphocytic lesions (JLI) to lesions characterized mainly by mucin deposition (papulonodular mucinosis). Clearly, much overlapping exists within the pathological spectrum of dermal LE.

We suggest to classify the specific cutaneous lesions of LE into dermo-epidermal, dermal and hypodermal variants of LE, as outlined in table 1 . We believe that this classification is logical and simple. The subset of dermal LE is a relatively homogenous subset of patients with a favourable prognosis, except for the group of patients with papulonodular mucinosis whose prognosis is more uncertain and in whom an association with systemic LE is often reported [13, 23, 24].

\section{References}

1 Caputo R, Marzano AV, Tourlaki A, Marchini M: Reticular erythematous mucinosis occurring in a brother and sister. Dermatology 2006; 212:385-387.

2 Perry HO, Kierland RR, Montgomery $\mathrm{H}$ : Plaque-like form of cutaneous mucinosis. Arch Dermatol 1960;82:980-985.

3 Steigleder GK, Gartmann H, Linker U: REM syndrome: reticular erythematous mucinosis (round-cell erythematosis), a new entity? $\mathrm{Br} \mathrm{J}$ Dermatol 1974;91:191-199.

4 Adamski F, Le Gall H, Chevrant-Breton J: Positive photobiological investigation in reticular erythematous mucinosis syndrome. Photodermatol Photoimmunol Photomed 2004; 20:235-238.
5 Micalizzi C, Parodi A, Rebora A: Myopathy, destructive arthropathy and peripheral neuropathy in a patient with reticular erythematous mucinosis and monoclonal gammopathy. Dermatology 1999;199:371-372.

6 Sidwell RU, Francis N, Bunker CB: Hormonal influence on reticular erythematous mucinosis. Br J Dermatol 2001;144:633-634.

7 Del Pozo J, Martinez W, Almagro M, Yebra MT, Garcia-Silva J, Fonseca E: Reticular erythematous mucinosis syndrome: report of a case with positive immunofluorescence. Clin Exp Dermatol 1997;22:234-236.

8 Velasco JA, Santos JC, Villabona B, Santana J: Reticular erythematous mucinosis and acral papulokeratotic lesions associated with myxoedema due to Hashimoto thyroiditis. Dermatology 1992;184:73-77.
9 Braddock SW, Davis CS, Davis RB: Reticular erythematous mucinosis and thrombocytopenic purpura: report of a case and review of the world literature, including plaquelike cutaneous mucinosis. J Am Acad Dermatol 1988;19: 859-868.

10 Dijkmans BA, Bergman W, Eulderink F, Meijers KA: Reticular erythematous mucinosis syndrome in a patient with polyarthritis. Acta Derm Venereol 1986;66:442-445.

11 Del Pozo J, Pena C, Almagro M, Yebra MT, Martinez W, Fonseca E: Systemic lupus erythematosus presenting with a reticular erythematous mucinosis-like condition. Lupus 2000;9: 144-146. 
12 Lowe L, Rapini RP, Golitz LE, Johnson TM: Papulonodular dermal mucinosis in lupus erythematosus. J Am Acad Dermatol 1992;27: 312-315.

13 Schneider GA, Lipsker D, Grosshans E: Papulonoduläre Muzinose als Begleiterkrankung bei Kollagenosen. Z Hautkr 1998;73:678681.

14 Dippel E, Poenitz N, Klemke CD, Orfanos CE, Goerdt S: Familial lymphocytic infiltration of the skin: histochemical and molecular analysis in three brothers. Dermatology 2002;204:1216.

15 Ashworth J, Morley WN: Jessner and Kanof's lymphocytic infiltration of the skin: a familial variant. Dermatologica 1988;177:120-122.
16 Toonstra I, van der Putte SC, de la Faille HB, van Vloten WA: Familial Jessner's lymphocytic infiltration of the skin, occurring in a father and daughter. Clin Exp Dermatol 1993;18: 142-145.

17 Jessner M, Kanof B: Lymphocytic infiltration of the skin. Arch Dermatol 1953;68:447-449.

18 Lipsker D, Mitschler A, Grosshans E, Cribier B: Could Jessner's lymphocytic infiltrate of the skin be a dermal variant of lupus erythematosus? An analysis of 210 cases. Dermatology 2006;213:15-22.

19 Dekle CL, Mannes KD, Davis LS, Sangueza OP: Lupus tumidus. J Am Acad Dermatol 1999;41:250-253.

20 Kuhn A, Sonntag M, Ruzicka T, Lehmann P, Megahed M: Histopathologic findings in lupus erythematosus tumidus: review of 80 patients. J Am Acad Dermatol 2003;48:901-908.
21 Gilliam JN: The cutaneous signs of lupus erythematosus. Contin Educ Fam Physician 1977; 6:34-40.

22 Marzano AV, Tanzi C, Caputo R, Alessi E: Sclerodermic linear lupus panniculitis: report of two cases. Dermatology 2005;210:329_ 332.

23 Pandya AG, Sontheimer RD, Cokerell CJ, Takashima A, Piepkorn M: Papulonodular mucinosis associated with systemic lupus erythematosus: possible mechanisms of increased glycosaminoglycan accumulation. J Am Acad Dermatol 1995;32:199-205.

24 Rongioletti F, Rebora A: Updated classification of papular mucinosis, lichen myxedematosus, and scleromyxedema. J Am Acad Dermatol 2001;44:273-281. 